\title{
Canton de Châtillon-sur-Loire
}

$\mathrm{n}^{\circ} 034434$

Frédéric Bordeau

\section{(2) OpenEdition}

Journals

Édition électronique

URL : http://journals.openedition.org/adlfi/14265

ISSN : 2114-0502

Éditeur

Ministère de la culture

Référence électronique

Frédéric Bordeau, «Canton de Châtillon-sur-Loire », ADLFI. Archéologie de la France - Informations [En ligne], Centre, mis en ligne le 20 mars 2015, consulté le 19 avril 2019. URL : http:// journals.openedition.org/adlfi/14265

Ce document a été généré automatiquement le 19 avril 2019

(C) Ministère de la Culture et de la Communication, CNRS 


\title{
Canton de Châtillon-sur-Loire
}

\author{
$n^{\circ} 034434$
}

\section{Frédéric Bordeau}

Lien Atlas (MCC) :

http://atlas.patrimoines.culture.fr/atlas/trunk/index.php?

ap_theme=DOM_2.01.02\&ap_bbox $=2.684 ; 47.536 ; 2.803 ; 47.615$

1 Cette année, la prospection a été étendue à l'ensemble du canton de Châtillon, de façon à compléter les données des prospections pédestres menées depuis près de dix ans sur cette zone.

2 La saison a livré les informations suivantes sur le lieu-dit du Pont des Beurthes (Beaulieusur-Loire) : le site, photographié pour la première fois en 97 , a pu être prospecté dans les meilleures conditions cette année, le blé ayant remplacé le colza. En plus de l'enclos fossoyé repéré l'année précédente, les fondations d'un vaste bâtiment apparaissaient sous forme de traces légèrement plus claires dans les céréales. Le plan observé fait penser à une villa à galerie de façade, mais dans ce cas, et bien que l'orientation du bâtiment soit en accord avec celle de l'enclos, l'ouverture observée dans ce dernier (au nord-ouest) se trouverait sur l'arrière de la villa, ce qui semble un peu étonnant. Faut-il y voir deux états successifs avec une villa succédant à une ferme indigène ou un autre type d'installation (par exemple un relais routier le long de la voie qui passe à quelques mètres de l'angle sud-ouest de l'enclos)?

3 Sur les communes de Châtillon et Saint-Firmin, les fossés parallèles de plusieurs chemins disparus ont été photographiés. Après un premier examen, la plupart d'entre eux semble relier les principaux sites d'époque romaine et en particulier ceux liés à l'exploitation du minerai de fer (la Motte-Saint-Firmin, Ganneset Châtillon).

4 Des semis de fosses, comparables à ceux observés sur Châtillon et Beaulieu, ont été repérés sur la commune d'Autry-le-Châtel. Ils sont situés à proximité d'une zone de ferriers importante. 
INDEX

Index géographique : Centre, Loiret (45), Châtillon-sur-Loire

operation Prospection aérienne (PA)

Index chronologique : Gallo-romain

Mots-clés : enclos, villa, fossé, semis 